\title{
Time in Bed, Sleep Sufficiency and Emotional and Behavioral Problems in a General Population of 10-12 Year Old Children
}

\author{
Hedvik Elisabeth Fosse*, ${ }^{*}$, Ståle Pallesen ${ }^{2,3}$, Mari Hysing ${ }^{1,4,5}$ and Kjell Morten Stormark ${ }^{1}$ \\ ${ }^{I}$ Centre for Child and Adolescent Mental Health and Welfare, Uni Health, Uni Research, Norway \\ ${ }^{2}$ Department of Psychosocial Science, University of Bergen, Norway \\ ${ }^{3}$ Norwegian Competence Center for Sleep Disorders, Haukeland University Hospital, Norway \\ ${ }^{4}$ Betanian Hospital, Bergen, Norway \\ ${ }^{5}$ Department of Biological and Medical Psychology, University of Bergen, Norway
}

\begin{abstract}
Objective: To examine the relationship between time in bed, sleep sufficiency and emotional and behavioral problems in a general population of children aged $10-12$ years $(\mathrm{N}=5095)$.

Methods: Emotional and behavioral problems were assessed using The Strength and Difficulties questionnaire, which was completed by children, parents and teachers. Data on time in bed, sleep sufficiency and potential confounders (gender, pubertal development, mother's education and family economy) were parent reported.

Results: Controlling for gender, pubertal development and socioeconomic status, childrens emotional and behavioral problems as rated by parents were related to insufficient sleep. Self-reported emotional symptoms and parent-reported conduct problems were associated with both shorter time in bed and insufficient sleep. Teacher-reported hyperactivity was associated with long time in bed.

Conclusions: Children with self-reported emotional symptoms or parent-reported conduct problems seem to spend too little time in bed and to obtain insufficient sleep.
\end{abstract}

Keywords: Time in bed, sleep sufficiency, emotional and behavioral problems, school-aged children, Norway.

There is accumulating evidence that children and adolescents sleep less than recommended. First, short time in bed is common. In a Norwegian study it was found that about $40 \%$ of 16-19 year olds spent less than 7 hours in bed at night on weekdays [1], despite the required sleep duration for this age group being between 8 and 9 hours [2]. Second, time in bed has decreased over the last decades. A comparison of three birth cohorts that were followed from birth to 16 years of age, showed a decreasing trend of sleep duration across cohorts [3].

Adequate sleep is increasingly seen as important for physical and mental health in children [4]. Among 12-18 year olds short self-reported sleep duration have been associated with especially self-reported depressive symptoms [5, 6] but also aggression [7] and inattention [8]. Moreover, in a longitudinal study of 11 year old children who reported to have obtained less sleep over time, exhibited higher levels of self-reported depression and lower levels of self-esteem three years later [9].

Gender, socioeconomic - and puberty status have been found to influence sleep duration in children. Girls have been found to sleep longer in adolescence [10], while there are no

*Address correspondence to this author at the Centre for Child and Adolescent Mental Health and Welfare, Uni Health, Uni Research, Norway; Tel: +47 5558 3133; Fax: +47 5558 8379; E-mail:Hedvik.Fosse@uni.no gender difference in sleep patterns in prepubertal children [11]. Also low socioeconomic status has been associated with short sleep duration $[12,13]$. The onset of puberty involves changes at multiple levels and is one factor thatinfluences both sleep and emotional and behavioral problems, however few studies have controlled for this factor. Sleepwake organization undergoes reorganization during the transition to adolescence and these changes seem to antedate bodily changes. These changes involve a delayed sleep phase, a marked tendency for later bedtimes and rise times [14] and shorter sleep, which is associated with increased levels of daytime sleepiness [15]. At the same time there is evidence for puberty-specific changes in neural systems involved in social and emotional processes [16]. Few studies have controlled for the effect of puberty, and consequently researchers have been concerned that there might be a risk for spurious associations between sleep and emotional and behavioral problems, and hence studies adequately controlling for confounding variables are called for [17].

In addition to the risk for spurious associations between sleep and emotional and behavioral problems, there is also a risk for a mono-informant bias in studies using the same informant on both sleep and emotional and behavioral problems. If all measures in one study are based on one reporter (e.g self, or parent), the findings could be attributed to common rater effects. Using the same informant to determine both sleep and emotional and behavioral problems may inflate correlations owing to item overlap [18]. A small num- 
ber of studies have included teacher's reports of emotional and behavioural problems, and the results are inconsistent. One study that included forty-nine 7- to 12-year-old children found associations between actigraphy measured short sleep duration and teacher-reported behavioural- [19]. Another study including one hundred and sixty-six elementary school children reported an association between actigraphy measured short sleep duration and emotional problems [20]. However, a study of 781 7-year olds did not find an association between actigraphy measured short sleep duration and teacher-reported behavioral problems [21]. When it comes to parent reported sleep duration, a study comprising 1182 6-11 year old children found that long duration was associated with teacher-reported hyperactivity [22]. However, studies using data from the Ontario Child Health Study found no associations between sleep duration and teacher reported emotional and behavioural problems in 1550 4-11 year olds [17] or in 980 13-16 year olds [23].

Based on these considerations the current study examines the associations between self-, parent- and teacher-reported emotional and behavioral problems and time in bed and sleep sufficiency in a large population based sample of 10-12 year olds. The paper extends the current literature by examining emotional and behavioral problems reported by multiple informants, at the same time as we control for gender, pubertal development and socioeconomic status, important potential confounders between sleep and emotional and behavioral problems. This study also investigated emotional and behavioral problems in relation to both time in bed and sleep sufficiency, because specific sleeping features have been found to have unique relations with symptoms of psychopathology $[24,25]$. It is possible that the relationship between sleep and emotional and behavioral problems are impacted by individual sleep need, so that a question of sufficient sleep may be more sensitive than a question about time in bed.

\section{METHODS}

\section{Sample}

The sample consists of participants in the second wave of the Bergen child study (BCS), carried out in the spring of 2006. The BCS is a longitudinal ongoing population-based study of children's mental health from primary school age to adolescence in all public, private, and special schools in the city of Bergen, the second largest city in Norway. The protocol and population of the BCS is described in detail in separate publications $[26,27]$. The main aims of the BCS were to establish reliable prevalence data for mental health problems in a total population, with special emphasis on co-morbidity, risk factors, protective factors and use of services. The present study includes data generated from a four-page screening questionnaire, and this questionnaire was administered to one of the parents, the child and the teacher. In the second wave of BCS 5781 children aged 10-12 years participated. Parent-reported time in bed (TIB) was available for 4921 children. Parent evaluation of sufficient sleep was available for 5095 children.

\section{Instruments and Procedure}

The parents were asked about the children's bedtime, wake time and an indicator of sufficient sleep. TIB was op- erationalized as the time difference between the following two questions: "When does he/she usually go to bed on school days?" and "When does he/she usually get up on school nights". The mean parent reported TIB was 9.74 hours $(\mathrm{SD}=0.58)$. The children were asked the same question and the mean child-reported TIB was $9.74(\mathrm{SD}=0.62)$. The correlation between self- and parent-reported TIB was high $(\mathrm{r}=0.758$, p. $<0.001)$, (standard deviation, SD_0.42). In addition the parents were asked if they felt their child obtained sufficient sleep during the night. The response alternatives was "too little", "somewhat little", "enough", "somewhat much" and "too much".

Children were screened for emotional and behavioral problems using self-, parent- and teacher ratings on the SDQ (Strengths and Difficulties Questionnaire; [28, 29]). The SDQ is a brief behavioral screening questionnaire that can be completed by the parents or teachers of children aged 4 to 16. Here we used three subscales of the SDQ: emotional symptoms ("worries", " unhappy", "somatic symptoms", "nervous in new situations" and "many fears "), conduct problems, ("tempers", "obedient", "fights or bullies", "lies or cheats" and "steals"), hyperactivity-inattention problems ("restless", "fidgety" "easily distracted", "thinks before acting" and "good attention"), each subscale comprising five items, which were scored on a three-point scale ("not true", "somewhat true", and "certainly true").

The child's pubertal maturation was estimated based on parent-report on a single item from the Pubertal Development Scale ("In puberty, the body changes from being a child into being an adult. In some children, the changes start early and, in others later. Compared with other children of the same age, did the pubertal development start earlier, at the same time or later?" scored on a five-point scale, ranging from: "much earlier', to"much later".

Socioeconomic status (SES) was measured by family economy and mother's education. Parents reported on family economy on a five-point scale ranging from "very good" to "very poor", Mother's education level was evaluated on a five point scale indicating their highest education level with the response alternatives "primary school"," Secondary school, theoretical", "College /university, up to 4 years" and" College/university, more than 4 years".

\section{Ethics}

The study was approved by the National Data Inspectorate and the Regional Committee for Medical and Health Research Ethics in western Norway. Written informed consent was obtained from all parents whose children were included in the study. Participants received no payment to participate

\section{Statistical Analysis}

TIB was converted into z-scores separately for each age group, in order to adjust for age-related development. Short TIB was operationalized as $\geq 1$ SD. Not short TIB was operationalized as $\leq 1 \mathrm{SD}$. "Insufficient sleep" was operationalized as a positive response to the alternatives; "too little" or "somewhat little". "Sufficient sleep" was operationalized as a positive response to; "enough", somewhat enough" or "too much". We compared children short TIB and those without short TIB. We also compared children with insufficient sleep and those with sufficient sleep. Pearson Chi-square tests and 
Table 1. Demographic and Clinical Characteristics in Children with Short/Not Short Time in Bed and Insufficient/Sufficient Sleep

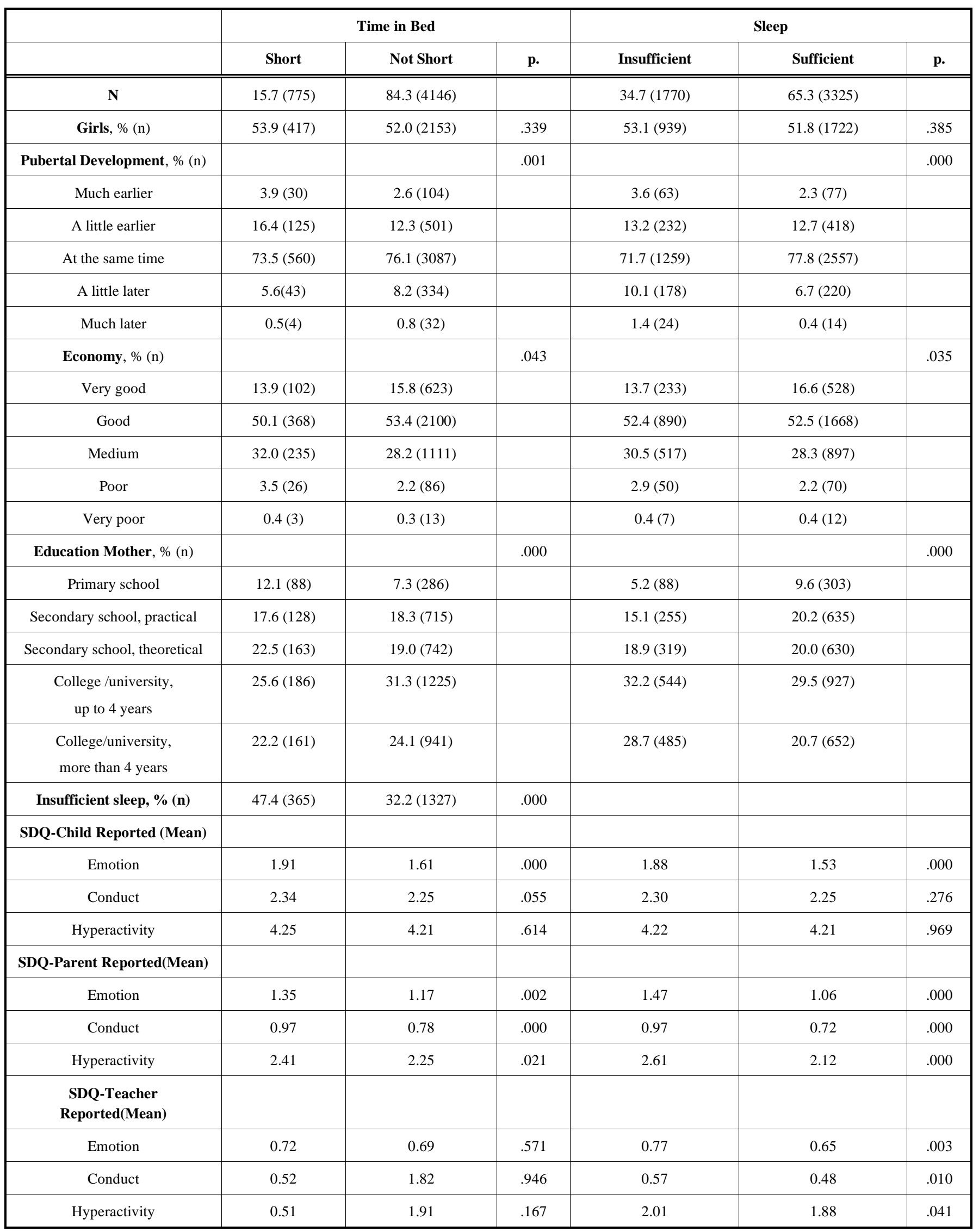


Kruskal-Wallis analysis of variance were used to examine these differences in demographics and clinical characteristics. In order to control for the influence of gender, pubertal maturity and SES when investigating the relationship between emotional and behavioral problems and time in bed and sleep sufficiency, two hierarchical linear regression analyses were conducted. At step 1 we entered gender ( $1=$ male, $2=$ female) and pubertal development ( $1=$ much earlier, 2=a little earlier", $3=$ at the same time", 4=a little later, $5=$ much later), mothers' education level $(1=$ primary school, $2=$ secondary school, practical, $3=$ secondary school. theoretical, $4=$ college/university, up to 4 years, $5=$ college/ university, more than 4 years") and family economy (1=very good, 2=good, 3=medium, 4=poor, 5=very poor). At step 2 we entered self-, parent- and teacher reported emotional symptoms and hyperactivity/inattention and conduct problems.

\section{RESULTS}

Demographic and Clinical Characteristics in Children with Short/Not Short TIB and Insufficient/Sufficient Sleep

775 children $(15.7 \%)$ had short TIB and 1770 children (34.7\%) had insufficient sleep. There was a significant association between TIB and pubertal development (children with short TIB reported earlier onset of puberty, $\mathrm{p}<.01$ ), SES (children with short TIB reported somewhat poorer economy, $\mathrm{p}<.05$ ), and had mothers with less education, $\mathrm{p}<.05$ ), while there were no associations with gender. There was also a significant association also between the sleep sufficiency groups and pubertal development (children with not sufficient sleep had earlier onset of puberty, $\mathrm{p}<.01$ ), SES (children with not sufficient sleep had somewhat poorer economy, $\mathrm{p}<.05$, and had mothers with lower education level, $\mathrm{p}<.05$ ), while there were no associations with gender (see Table 1). In the whole sample 3757 children (59.0\%) reported to be in a household with their mother and father.

When it comes to emotional and behavioral problems in children with short/not short TIB and insufficient/sufficient sleep, there was a significant association between the selfreported emotional symptoms and both TIB and sufficiency (children with short TIB reported more emotional symptoms, $\mathrm{p}<.01)$. When it comes to parent-reported SDQ scores, all emotional and behavioral problems scores were significantly elevated in children with short TIB or insuficcient sleep, compared to children without short TIB or sufficient sleep. Regarding teacher-reported SDQ scores, there was a significant association between all of the SDQ scores and sufficiency (children with not sufficient sleep had more teacher reported symptoms). There were no significant association between teacher reported SDQ scores and TIB.

\section{Sleep Sufficiency in Children with Short TIB}

In all, $47.4 \%(n=365)$ of the children with short TIB had insufficient sleep, compared to $32.3 \%(n=1327)$ in not short TIB group $(\mathrm{p}<.01)$ (see Table $\mathbf{1})$.

Table 2. Hierarchical Regression Examining the Contribution of Emotional Symptoms, Hyperactivity and Conduct Problems to Time in Bed, Accounting for Gender, Pubertal Development and Socioeconomic Status

\begin{tabular}{|c|c|c|c|c|c|}
\hline & \multicolumn{5}{|c|}{ Time in Bed $(Z)$} \\
\hline Gender & & & & -.018 & .232 \\
\hline Pubertal development & & & & .070 & 0.00 \\
\hline Family economy & & & & -.009 & .564 \\
\hline Step 2 & .011 & .006 & .001 & & \\
\hline SR Emotion & & & & -.041 & .024 \\
\hline SR Hyperactivity & & & & -.013 & .385 \\
\hline PR hyperactivity & & & & -.012 & .551 \\
\hline PR conduct & & & & -.064 & .000 \\
\hline TR emotional & & & & .016 & .359 \\
\hline TR hyperactivity & & & & .043 & .035 \\
\hline TR conduct & & & & .010 & .585 \\
\hline
\end{tabular}

Note. Gender ( $1=$ male, $2=$ female), Pubertal development $(1=$ much earlier, $2=$ a little earlier", $3=$ at the same time", $4=$ a little later, $5=$ much later $)$, mothers education $(1=$ primary school, $2=$ secondary school, practical, $3=$ secondary school, theoretical $4=$ college/university, up to 4 years, $5=$ college/university, more than 4 years "), family economy( $1=$ very good, $2=$ good, $3=$ average, $4=$ bad, $5=$ very bad) 


\section{Emotional and Behavioral Problems as Predictors of TIB}

Hierarchical multiple regression was used to assess the ability of emotional and behavioral problems to predict levels of age-adjusted TIB, after controlling for the influence of gender, pubertal maturation, mothers education and family economy (Table 2). Gender, pubertal maturation, mothers education and family economy were entered at step 1 , explaining $0.6 \%$ of the variance in TIB. After entry of emotional and behavioral problems at step 2 this explained an additional $0.6 \%$ of the variance in TIB. The final model explained $1.1 \%$ of the variance in TIB. Self-reported emotional symptoms and parent-reported hyperactivity/inattention was significantly associated with short TIB. Teacherreported conduct problems were associated with long TIB.

\section{Emotional and Behavioral Problems as Predictors of Sleep Sufficiency}

Hierarchical multiple regression was also used to assess the ability of emotional and behavioral problems to predict levels of age-adjusted sleep sufficiency, after controlling for the influence of gender, pubertal maturation, mothers education and family economy (Table 3). Gender and pubertal maturation mother's education and family economy were entered at step 1, explaining $1.8 \%$ of the variance in sleep sufficiency. After entry of emotional and behavioral problems at step 2 this explained an additional $3.9 \%$ of the variance in sleep sufficiency. The total variance explained by the model was $5.7 \%$ of the variance in sleep sufficiency. Self- reported emotional symptoms and all parent-reported emotional and behavioral problems predicted insufficient sleep with parent-reported hyperactivity problems recording the highest beta value.

\section{DISCUSSION}

In this study of 10-12 year old children, after controlling for some important shared risk factors, all parent reported emotional and behavioral problems variables were related to insufficient sleep. Teacher-reported hyperactivity was associated with longer time in bed, but not insufficient sleep. Two emotional and behavioral problems were related to both short time in bed and insufficient sleep; self-reported emotional symptoms and parent-reported conduct problems. Few studies have earlier controlled for the effect of puberty and studies adequately controlling for confounding variables are called for [17]. Gender [10], socioeco-nomic status [12, $13]$ and puberty $[16,30]$ are factors that can influence both sleep and emotional and behavioral functioning. It has to be noted that although time in bed and insufficient sleep were significantly associated with some symptoms of emotional and behavioral problems, after accounting for shared risk factors, the variance accounted for by emotional and behavioral problems was small; $1.1 \%$ for time in bed and $5.7 \%$ for sleep sufficiency.

The first finding in the present study was that all parent reported emotional and behavioral problems variables were related to insufficient sleep as judged by parents. However, it is interesting that none of the teacher reported emotional and

Table 3. Hierarchical Regression Examining the Contribution of Emotional Symptoms, Hyperactivity and Conduct Problems to Sleep Sufficiency, Accounting for Gender, Pubertal Development and Socioeconomic Status

\begin{tabular}{|c|c|c|c|c|c|}
\hline & \multicolumn{5}{|c|}{ Sleep Sufficiency } \\
\hline & R Square & R Square Change & p. & $\boldsymbol{\beta}$ & $\mathbf{p}$ \\
\hline Step 1 & .018 & & .000 & & \\
\hline Gender & & & & -.012 & .889 \\
\hline Pubertal development & & & & .009 & .283 \\
\hline Mothers education & & & & -.148 & .000 \\
\hline Family economy & & & & -.039 & .000 \\
\hline Step 2 & .057 & .039 & .000 & & \\
\hline SR emotional & & & & -.043 & .015 \\
\hline SR hyperactivity & & & & .022 & .136 \\
\hline SR conduct & & & & .012 & .443 \\
\hline PR emotional & & & & -.088 & .000 \\
\hline PR hyperactivity & & & & -.101 & .000 \\
\hline PR conduct & & & & -.057 & .001 \\
\hline TR emotional & & & & .012 & .463 \\
\hline TR hyperactivity & & & & -.017 & .376 \\
\hline TR conduct & & & & .029 & .099 \\
\hline
\end{tabular}

Note. Gender ( $1=$ male, $2=$ female), Pubertal development ( $1=$ much earlier, $2=$ a little earlier", $3=$ at the same time", $4=$ a little later, $5=$ much later), mothers education $(1=$ primary school, $2=$ secondary school, practical, $3=$ secondary school, theoretical $4=$ college/university, up to 4 years, $5=$ college/university, more than 4 years "), family economy $(1=$ very good, $2=$ good, $3=$ average, $4=$ bad, $5=$ very bad). 
behavioural problems, and only self reported emotional problems, were related to the same sleep variable. It is possible that the common rater effects may explain these findings. Gregory and O`Connor (2002) have pointed out that parent reports incorporate a number of methodological problems, including rater bias. Using the same informant (e.g., self, or parent report) to determine both sleep and emotional and behavioral problems may inflate correlations owing to item overlap. The contributions of different informants may provide valuable information pertaining to the emotional and behavioural functioning of children and adolescents, as each informant may provide unique information about the functioning of a particular child or adolescent. Child behaviours may be situation specific, with certain emotional and/or behavioural problems occurring in only certain settings and different informants may observe different behaviours [31].

The second finding in the present study was that teacherreported hyperactivity was associated with longer time in bed, but not insufficient sleep, after accounting for gender, pubertal development and socioeconomic status. Based on the published clinical literature we would have excepted that children with more hyperactive problems would not be reported by their parents to sleep as much as children with less hyperactive problems [32, 33], even if objective studies are somewhat contradictory in this regard [34]. However, it is interesting that also one of the few other studies that have included teachers found that longer sleep duration occurred more frequently in children with hyperactivity problems at school [22].

The third finding in the present study; that self-reported emotional problems are associated with both short time in bed and insufficient sleep is in line with previous crosssectional studies in both the population-based [5, 35] and clinical [36] samples. Objective assessment by actigraphy has also shown that shorter sleep time is associated with more depressive symptoms as self-rated by 8 - to 9 -year-old children [37] and similar results have been provided by Sadeh et al. [38] for children aged 7-13 years. One possible explanation for the association between self-reported emotional symptoms and short sleep time is that these children experience greater stress and arousal on school nights due to school-based fears, and that this might play a role in putting off going to bed [36]. Or that these children are more likely to refuse to sleep alone, which could result in bedtime resistance and shortened sleep time.

The fourth finding in the present study was that parentreported conduct problems were associated with both short time in bed and insufficient sleep. This finding is consistent with a cross-sectional study among juvenile and young offenders that found that that increased self-reported hostility was predictive of reduced current hours of sleep [7]. Also in a longitudinal study less self-reported delinquent behavior contributed to longer time in bed [39]. A tentative explanation for the association between parent-reported conduct problems and short time in bed and insufficient sleep might be that children with conduct problems are more likely to show bedtime resistances than other children. In another study among somewhat younger children; 6-8 years, also measuring psychopathology with SDQ, conduct problems were related to bedtime resistance [25]. Another explanation might be that this association can be explained by a common rater effect.

\section{Limitations}

Unfortunately, we have no information if TIB was controlled by the parents. However, as the children are 10-12 years it is likely that the bedtime and waketime to a large extent are set by the parents. If TIB is controlled by the parent our findings may reflect more about the child's environment than about the childs preferences. In addition, asking for usual bedtimes and wake-up times at school days may also influence the validity of the data by. Such data could be more vulnerable to social desirability bias than yesterday recalls. Secondly, we have no objective data on time in bed or sleep sufficiency, and it is therefore important to emphasize that this study focuses on parental perceptions of sleep, which could be different from objective sleep. Thus, future studies should include objective measures, such as actigrafy, in order to corroborate the subjective reports. Thirdly, even if we controlled for important potential confounders like gender, pubertal development, mother's education and family economy, a number of other factors remain unaccounted, for example parental conflict which may disrupt the sleep of the child [40]. At the same time inter-parental conflict is also associated with an array of emotional and behavioural problems [41]. Hence, inclusion of for example parental conflict as an additional confounder to be controlled for might artificially reduce the magnitude of the association between sleep and psychopahology. Finally, due to the cross-sectional design of the current study we are precluded from making any conclusions concerning causality.

The main conclusion from the current study is that children with self-reported emotional problems and parentreported conduct problems seem to spend too little time in bed and to obtain insufficient sleep.

\section{ACKNOWLEDGEMENTS}

Centre for Child and Adolescent Mental Health and Welfare, Uni Health, Uni Research, is responsible for the Bergen Child study, funded by the University of Bergen, the Norwegian Directorate for Health and Social Affairs, and the Western Norway Regional Health Authority. We are grateful to the children, parents and teachers participating in the BCS, and to the other members of the project group for making the study possible.

\section{ABBREVIATIONS \\ $\mathrm{BCS}=$ Bergen child study \\ TIB $=$ Time in bed \\ SES = Socioeconomic status}

\section{REFERENCES}

[1] Pallesen S, Saxvig IW, Molde H, Sørensen E, WilhelmsenLangeland A, Bjorvatn B. Brief report: Behaviorally induced insufficient sleep syndrome in older adolescents: Prevalence and correlates. J Adolesc 2011; 34(2): 391-5.

[2] Carskadon MA, Harvey K, Duke P, Anders TF, Litt IF, Dement WC. Pubertal changes in daytime sleepiness. Sleep 1980; 2(4): 453-60.

[3] Iglowstein I, Jenni OG, Molinari L, Largo RH. Sleep duration from infancy to adolescence: Reference values and generational trends. Pediatrics 2003; 111(2): 302-7. 
[4] Dahl RE. The regulation of sleep and arousal: development and psychopathology. Dev Psychopathol 1996; 8(1): 3-27.

[5] Yen CF, Ko CH, Yen JY, Cheng CP. The multidimensional correlates associated with short nocturnal sleep duration and subjective insomnia among Taiwanese adolescents. Sleep 2008; 31(11): 1515-25.

[6] Wolfson AR, Carskadon MA. Sleep schedules and daytime functioning in adolescents. Child Dev 1998; 69(4): 875-87.

[7] Ireland JL, Culpin V. The relationship between sleeping problems and aggression, anger, and impulsivity in a population of juvenile and young offenders. J Adolesc Health 2006; 38(6): 649-55.

[8] Lam LT, Yang L. Duration of sleep and ADHD tendency among adolescents in China. J Atten Disord 2008; 11(4): 437-44.

[9] Fredriksen K, Rhodes J, Reddy R, Way N. Sleepless in Chicago: Tracking the effects of adolescent sleep loss during the middle school years. Child Dev 2004; 75(1): 84-95.

[10] Olds T, Blunden S, Petkov J, Forchino F. The relationships between sex, age, geography and time in bed in adolescents A meta-analysis of data from 23 countries. Sleep Med Rev 2010; 14(6): 371-8.

[11] Wolfson AR. Sleeping patterns of children and adolescents Developmental trends, disruptions, and adaptations. Child Adolesc Psychiatr Clin N Am 1996; 5(3): 549.

[12] BaHammam A, AlFaris E, Shaikh S, Bin Saeed A. Prevalence of sleep problems and habits in a sample of Saudi primary school children. Ann Saudi Med 2006; 26(1): 7-13.

[13] Dollman J, Lewis F. Trends in health attitudes and self-perceptions among school-age South Australians between 1985 and 2004. Aust N Z J Public Health 2007; 31(5): 407-13.

[14] Laberge L, Petit D, Simard C, Vitaro F, Tremblay RE, Montplaisir J. Development of sleep patterns in early adolescence. J Sleep Res 2001; 10(1): 59-67.

[15] Carskadon MA, Wolfson AR, Acebo C, Tzischinsky O, Seifer R. Adolescent sleep patterns, circadian timing, and sleepiness at a transition to early school days. Sleep 1998; 21(8): 871-81.

[16] Campbell IG, Darchia N, Khaw WY, Higgins LM, Feinberg I. Sleep EEG evidence of sex differences in adolescent brain maturation. Sleep 2005; 28(5): 637-43.

[17] Coulombe JA, Reid GJ, Boyle MH, Racine Y. Concurrent associations among sleep problems, indicators of inadequate sleep, psychopathology, and shared risk factors in a population-based sample of healthy ontario children. J Pediatr Psychol 2010; 35(7):790-9.

[18] Gregory AM, O'Connor TG. Sleep problems in childhood: A longitudinal study of developmental change and association with behavioral problems. J Am Acad Child Adolesc Psychiatry 2002; 41(8): 964-71.

[19] Aronen ET, Paavonen EJ, Fjallberg M, Soininen M, Torronen J. Sleep and psychiatric symptoms in school-age children. J Am Acad Child Adolesc Psychiatry 2000; 39(4): 502-8.

[20] El-Sheikh M, Buckhalt JA, Cummings EM, Keller P. Sleep disruptions and emotional insecurity are pathways of risk for children. J Child Psychol Psychiatry 2007; 48(1): 88-96.

[21] Nixon GM, Thompson JMD, Han DY, et al. Short sleep duration in middle childhood: Risk factors and consequences. Sleep 2008; 31(1): 71-8.

[22] Bos SC, Gomes A, Clemente V, et al. Sleep and behavioral/ emotional problems in children: a population-based study. Sleep Med 2009; 10(1): 66-74.

[23] Coulombe JA, Reid GJ, Boyle MH, Racine Y. Sleep problems, tiredness, and psychological symptoms among healthy adolescents. J Pediatr Psychol 2011; 36 (1): 25-35.
[24] Stein MA, Mendelsohn J, Obermeyer WH, Amromin J, Benca R. Sleep and behavior problems in school-aged children. Pediatrics 2001; 107(4): E60.

[25] Smedje H, Broman JE, Hetta J. Associations between disturbed sleep and behavioural difficulties in 635 children aged six to eight years: a study based on parents' perceptions. Eur Child Adolesc Psychiatry 2001; 10(1): 1-9.

[26] Heiervang E, Stormark KM, Lundervold AJ, et al. Psychiatric disorders in Norwegian 8-to 10-year-olds: An epidemiological survey of prevalence, risk factors, and service use. J Am Acad Child Adolesc Psychiatry 2007; 46(4): 438-47.

[27] Stormark KM, Heiervang E, Heimann M, Lundervold A, Gillberg C. Predicting nonresponse bias from teacher ratings of mental health problems in primary school children. J Abnorm Child Psychol 2008; 36(3): 411-9.

[28] Goodman, R. The extended version of the strengths and difficulties questionnaire as a guide to child psychiatric caseness and consequent burden. J Child Psychol Psychiatry Allied Disciplines, 1999; 40(5): 791-799.

[29] Goodman, R. Psychometric properties of the strengths and difficulties questionnaire. J Am Acad Child Adolescent Psychiatry, 2001; 40(11): 1337-1345.

[30] Jenni OG, Va Reen E, Carskadon MA. Regional differences of the sleep electroencephalogram in adolescents. J Sleep Res 2005; 14(2): 141-7.

[31] Renk K. Cross-informant ratings of the behavior of children and adolescents: The "Gold Standard". J Child Fam Stud 2005; 14(4): 457-68.

[32] Gruber R, Sadeh A, Raviv A. Instability of sleep patterns in children with attention-deficit/hyperactivity disorder. J Am Acad Child Adolesc Psychiatry 2000; 39(4): 495-501.

[33] Corkum P, Tannock R, Moldofsky H. Sleep disturbances in children with attention-deficit/hyperactivity disorder. J Am Acad Child Adolesc Psychiatry 1998; 37(6): 637-46.

[34] Cortese S, Mid EK, Yateman N, Mouren MC, Lecendreux M. Sleep and alertness in children with attention-deficit/hyperactivity disorder: a systematic review of the literature. Sleep 2006; 29(4): 504-11.

[35] Gangwisch JE, Babiss LA, Malaspina D, Turner JB, Zammit GK, Posner K. Earlier parental set bedtimes as a protective factor against depression and suicidal ideation. Sleep 2010; 33(1): 97-106.

[36] Hudson JL, Gradisar M, Gamble A, Schniering CA, Rebelo I. The sleep patterns and problems of clinically anxious children. Behav Res Ther 2009; 47(4): 339-44.

[37] El-Sheikh M, Erath SA, Keller PS. Children's sleep and adjustment: the moderating role of vagal regulation. J Sleep Res 2007; 16(4): 396-405.

[38] Sadeh A, Gruber R, Raviv A. Sleep, neurobehavioral functioning, and behavior problems in school-age children. Child Dev 2002; 73(2): 405-17.

[39] Meijer AM, Reitz E, Dekovic M, van den Wittenboer GLH, Stoel RD. Longitudinal relations between sleep quality, time in bed and adolescent problem behaviour. J Child Psychol Psychiatry 2010; 51(11): 1278-86.

[40] El-Sheikh M, Buckhalt JA, Mize J, Acebo C. Marital conflict and disruption of children's sleep. Child Dev 2006; 77(1): 31-43.

[41] Cummings EM, Davies PT. Effects of marital conflict on children: recent advances and emerging themes in process-oriented research. J Child Psychol Psychiatry Allied Discip 2002; 43(1): 31-63.

Received: April 08, 2011

Revised: May 18, 2011

Accepted: July 07, 2011

(c) Fosse et al.; Licensee Bentham Open.

This is an open access article licensed under the terms of the Creative Commons Attribution Non-Commercial License (http://creativecommons.org/licenses/by-nc/3.0/) which permits unrestricted, non-commercial use, distribution and reproduction in any medium, provided the work is properly cited. 